Original article

Ukr Neurosurg J. 2021;27(4):

doi: $10.25305 /$ unj. 236138

\title{
Cognitive evoked potentials in the diagnosis of post-concussion syndrome due to blast mild traumatic brain injury
}

Yurii V. Zavaliy ${ }^{1}$, Oleksandr S. Solonovych ${ }^{2}$, Vadym V. Biloshitsky ${ }^{1}$, Albina I. Tretiakova ${ }^{2}$, Lidia L. $^{2}$ Chebotariova ${ }^{2}$, Liudmyla M. Suliy ${ }^{2}$

1. Neurotrauma Department, Romodanov Neurosurgery Institute, Kyiv, Ukraine

2. Functional Diagnostics Department Romodanov Neurosurgery Institute, Kyiv, Ukraine

Received: 30 June 2021

Accepted: 15 October 2021

Address for correspondence: Vadym V. Biloshitsky, Department of Neurotrauma, Romodanov Neurosurgery Institute, 32 Platona Maiborody st., Kyiv, 04050, Ukraine, e-mail: headinjury@ukr.net
Hostilities in the East of Ukraine are characterized by the use of new weapons, including rocket artillery, rocket-propelled grenades and landmines. This has led to an increase in the number of victims with blast mild traumatic brain injury (BMTBI) and the need to provide them with effective assistance and rehabilitation. An important task is to improve the BMTBI diagnosis by specifying the objective criteria for structural and functional disorders of the central nervous system. This will improve the prognosis of the course of BMTBI in the injured and the treatment program, including personalized, to prevent the development of persistent neurological deficit.

Objective: to investigate the possibilities of the cognitive evoked potentials (CEP) method for the objective diagnosis of cognitive disorders in postconcussion syndrome (PCS) BMTBI.

Materials and methods. The study involved 115 men with PCS (main group) and 30 healthy individuals (control group). The cognitive functions of the study participants were studied using the questionnaire "Cicerone". The neurophysiological method for assessing the functional state of the brain involved the registration of CEP, event-related (P300 CEP).

Results. The selection of a subgroup of patients with PCS, characterized by a predominance of cognitive impairments, allowed us to trace the relationship between the results of neurophysiological studies with the cognitive indicators of patients with BMTBI. P300 latency indices are inversely proportional to cognitive assessment the questionnaire "Cicerone" and statistically significantly depend on the severity of cognitive impairment.

Conclusions. The CEP P300 method can be an effective means of objectifying the degree of cognitive impairment in patients with PCS due to BMTBI.

Key words: blast mild traumatic brain injury; post-concussion syndrome; cognitive impairment; cognitive evoked potentials; P300

\section{Introduction}

The blast traumatic brain injury (TBI) is a "silent epidemic of an invisible wound" in countries involved in military conflicts [1]. It is noted that while serving in Iraq and Afghanistan, $10-20 \%$ of US military personnel received TBI [2]. Of all injuries sustained by US military personnel during operations in these countries, $56-78 \%$ were injuries due to explosive shells, landmines and rocket-propelled grenades [3]. This gives grounds to consider the blast TBI as a marker trauma of servicemen in modern hostilities [1].

In the period from 2000 to 2014 in the US military there has been registered about 320 thousand cases of TBI, mostly received during hostilities [4]. Only about $2.8 \%$ of them were classified as severe injuries, while in most cases - mild TBI. The total number of cases is considered to be underestimated, since blast mild TBI (BMTBI) often remains undiagnosed and untreated due to imperfect screening tools, unclear diagnostic criteria, and lack of means to objectify or visualize damage [5]. The military conflict in the East of Ukraine is characterized by the simultaneous use of modern personal protective equipment and new types of weapons, in particular rocket artillery, rocketpropelled grenades and landmines. This has led to an increase in the number of victims with blast injury and the need to provide them with effective assistance and rehabilitation [6].

The mechanisms of blast and "civilian" TBI differ. If during peace-time injury the brain suffers due to the action of rotational and inertial forces, as well as local traumatic effect, the blast injuries are the result of the wave of pressure transmitted from a distance through the air [7]. According to the classical definition of C.J. Clemedson (1956) [8], a blast injury is biophysical and pathophysiological changes as a result of exposure to the explosion itself or a related shock wave. A blast injury, with clinical signs of mild TBI, may be accompanied by significant morphological changes (brain edema, neuroinflammation, vasospasm, diffuse axonal damage 
and neuronal death, secondary astrogliosis). At the cellular level, blast traumatic brain injury is characterized by multiple heterogeneous disorders, including increased $\beta$-amyloid precursor protein, increased expression of c-Myc, c-Fos and c-Jun protooncogenes, increased nitric oxide synthesis with the development of oxidative stress, impaired axonal transport, increased levels of TBI biomarkers - neuron-specific enolase (NSE), ubiquitin C-terminal hydrolase (UCH-L1) and glial fibrillar acidic protein (GFAP) [1].

Clinical signs of BMTBI are variable: headache, fatigue, tinnitus, irritability, neuropsychiatric and cognitive disorders. The latter can be temporary or permanent. The long-term nature of cognitive deficit may be associated with the fact that blast TBI increases the risk of remote development of neurodegenerative diseases such as Alzheimer's disease and chronic traumatic encephalopathy $[9,10]$.

The possibility of long-term persistence of neurological and cognitive deficits after mild TBI was the basis for the isolation of a separate nosological unit postconcussion syndrome (PCS). According to diagnostic criteria, PCS occurs as a result of a head injury that is severe enough to cause loss of consciousness and is characterized by at least three of the following: 1) complaints of discomfort (dizziness, general malaise and excessive tiredness or noise intolerance) and headache; 2) emotional changes (irritability, emotional lability or a certain level of depression and / or anxiety), 3) subjective complaints of difficulty concentrating and performing mental tasks, as well as memory problems without clear objective evidence, 4) insomnia, 5) decreased alcohol tolerance, 6) concern about these symptoms and fear of permanent brain damage up to hypochondria and acceptance of the role of the patient [11].

A characteristic feature of BMTBI is the frequent presence of concomitant post-traumatic stress disorder (PTSD). The presence of PTSD significantly complicates the diagnosis of BMTBI due to the similarity of symptoms. However, TBI is an organic injury to nerve tissue, while PTSD is a psychological response to a stressor and is not accompanied by physical changes. This difference leads to different approaches to the treatment of these conditions. If PTSD therapy mainly involves the normalization of the stress response with the help of psychological and pharmacological correction, the treatment of TBI should take into account structural and molecular biological changes to prevent their impact on the severity and duration of neurological deficits $[4,12]$.

Thus, an important task is to improve the diagnosis of MBTBI by specifying the objective criteria for structural and functional disorders of the central nervous system. This will improve the prognosis of the course of MBTBI in the injured and will contribute to specifying the treatment program, in particular personalized treatment, to prevent the development of persistent neurological deficits.

Objective: to invetigate the possibilities of the cognitive evoked potentials method for the objective diagnosis of cognitive disorders in post-concussion syndrome due to blast mild traumatic brain injury.

\section{Materials and methods}

The study involved 115 men with PCS (main group) and 30 healthy individuals (control group). The diagnosis of PCS after previous BMTBI (2014-2017) was established by a special military medical commission of Ukrainian Military Medical Academy based on the life record and clinical data, accompanying medical documentation. All patients were in the long term period of injury (from 6 months to 3 years). All individuals of the main and control groups gave written consent to conduct the research and process the information received.

Inclusion criteria in the study were: participation in hostilities, the presence of mild TBI due to mine explosion, age 18-45 years, no history of previous TBI, cerebrovascular disorders, surgery on the central nervous system. Exclusion criteria from the study were: previous TBI, any cerebrovascular accident, alcohol abuse, addictive substance abuse, psychiatric observation.

Among 115 surveyed, 103 (89.6 $\pm 5.6 \%)$ had higher education, $11(9.6 \pm 5.4 \%)$ had incomplete higher education, and $1(0.9 \pm 1.7 \%)$ had secondary education.

A single scheme for examining the consequences of BMTBI was followed: all patients underwent magnetic resonance imaging of the brain, duplex scanning of the vessels of the neck and intracranial blood flow, an otoneurologist and a neuroophthalmologist consultation. After careful collection of complaints and life record data, neurological status and cognitive functions were investigated using the questionnaire "Cicerone" [13], the neuropsychological test according to the Montreal Cognitive Assessment score (MoCA), to identify anxiety and depression - the Hospital Anxiety and Depression Score (HADS) with a score was used, to objectify psychasthenic disorders - the asthenic state scale (ASS) $[14,15]$.

The determination of diagnostic capabilities of the CEP P300 method for objectification of the presence and severity of cognitive impairment in patients with PCS after BMTBI have been carried out.

Neurophysiological methods for assessing the functional state of the brain involved the registration of cortical "evoked potentials (EPs) associated with the event" (CEP P300) and quantitative electroencephalography (qEEG) conducted on a 24-channel electroencephalograph "BRAIN-TEST" "DX system", Ukraine) according to standard parameters (sensitivity - $70 \mu \mathrm{V} / \mathrm{cm}$, time constant $-0.1 \mathrm{~s}$, filter $-40 \mathrm{~Hz}$ ). CEP P300 was recorded according to the standard method $[16,17]$ on a 4-channel myographic device "Neuro-MVP-4" ("Spectromed", Ukraine). Presenting in a random sequence the "odd-ball paradigm" series of two types of stimuli (clicks): significant (with a frequency of $2000 \mathrm{~Hz}$, the probability of $30 \%$ ) and nonsignificant (with a frequency of 1000 $\mathrm{Hz}$, the probability of $70 \%$ ), the stimulus duration $30-50$ ms, intensity 75-85 dB, period between stimuli - $1 \mathrm{~s}$, binaural stimulation through headphones, frequency $0.5-50.0 \mathrm{~Hz}$. The patient was in a soundproof and lightinsulated room, sitting in a special chair with his eyes closed. Scalp electrodes were placed at coordinates C3 and C4 according to the International System "10-20\%", the reference electrode was on the mastoid process, the

This article contains some figures that are displayed in color online but in black and white in the print edition 
ground electrode - Fpz. The patient pressed the joystick button with the dominant hand as soon as he heard a significant (target) stimulus. The analysis epoch is $500-700 \mathrm{~ms}$, the averaging number is $30-70$, separately for significant and nonsignificant stimuli.

The analysis of the registered CEP provided for: 1) assessment of behavioral data (time of motor response of the stimulus fixation, the number of errors - false triggers, omission of a significant stimulus), 2) calculation of CEP parameters. The P300 component in the range of 250-400 ms was verified, the latency and amplitude of the P1-N1-P2 and subsequent N2-P3-N3 complexes were determined, and changes in the form of the cognitive response and interhemispheric asymmetry of indicators were taken into account. An increase in the latency of CEP P300 compared to the age norm was interpreted as a sign of impaired signal recognition and differentiation (similar to dementia, attention deficit disorder, etc.), a decrease in P300 amplitude - as a decrease in short term memory $[16,17]$.

Mathematical processing of the obtained results was carried out by comparing the groups using the Mann Whitney test $(U)$ (the distribution of indicators in the groups did not correspond to the normal distribution law). To compare the frequencies, a contingency table was used to calculate the Pearson's chi-square test and the constraint force ( $\varphi$ or 0 ). In the case of age dependence of indicators as the "age norm" the upper limit of $95 \%$ of the indicator interval for healthy individuals, calculated from the regression equation was used. Frequency, selecting bias, 95\% confidence interval (CI), amplitude, median, interquartile range were used to describe groups. The critical level of significance ( $p)$ for testing statistical hypotheses when comparing groups was $<0.05$.

The study was conducted in accordance with the requirements of the 1975 Helsinki Declaration and the 1996-2013 editions. Recruitment of participants and data processing were carried out after written information consent.

The main results of our clinical and neurological, neuropsychological and neurophysiological studies have been published previously $[18,19]$.

\section{Results and discussion}

K.D. Cicerone and K. Kalmar (1995) [13] identified 4 clusters of symptoms and signs in the structure of PCS: affective, cognitive, somatic and sensory (Fig. 1).

Based on the prevalence of the frequency of significant cognitive impairments and the severity of clinical manifestations of BMTBI, three main variants for PCS in combat lesions of the central nervous system have been identified. Data on the frequency of detection of complaints, symptoms and signs of disorders in patients are given in Table. 1. Assessment of symptoms (signs) according to the items of questionnaire "Cicerone" [13]) was used to calculate scores in clusters: C somatic disorders, $\mathrm{K}$ - cognitive disorders, $\mathrm{A}$ - affective disorders. Assessment of symptoms (signs) ranged from 0 to 3 points: 0 - rarely observed, does not affect working capacity, 1 - noted frequently, sometimes impairs working capacity, 2 - noted frequently, may impair working capacity, 4 - noted constantly, unable to work. In each cluster, according to the assessment of the items of questionnaire and depending on the total score, the following gradations of impaiments

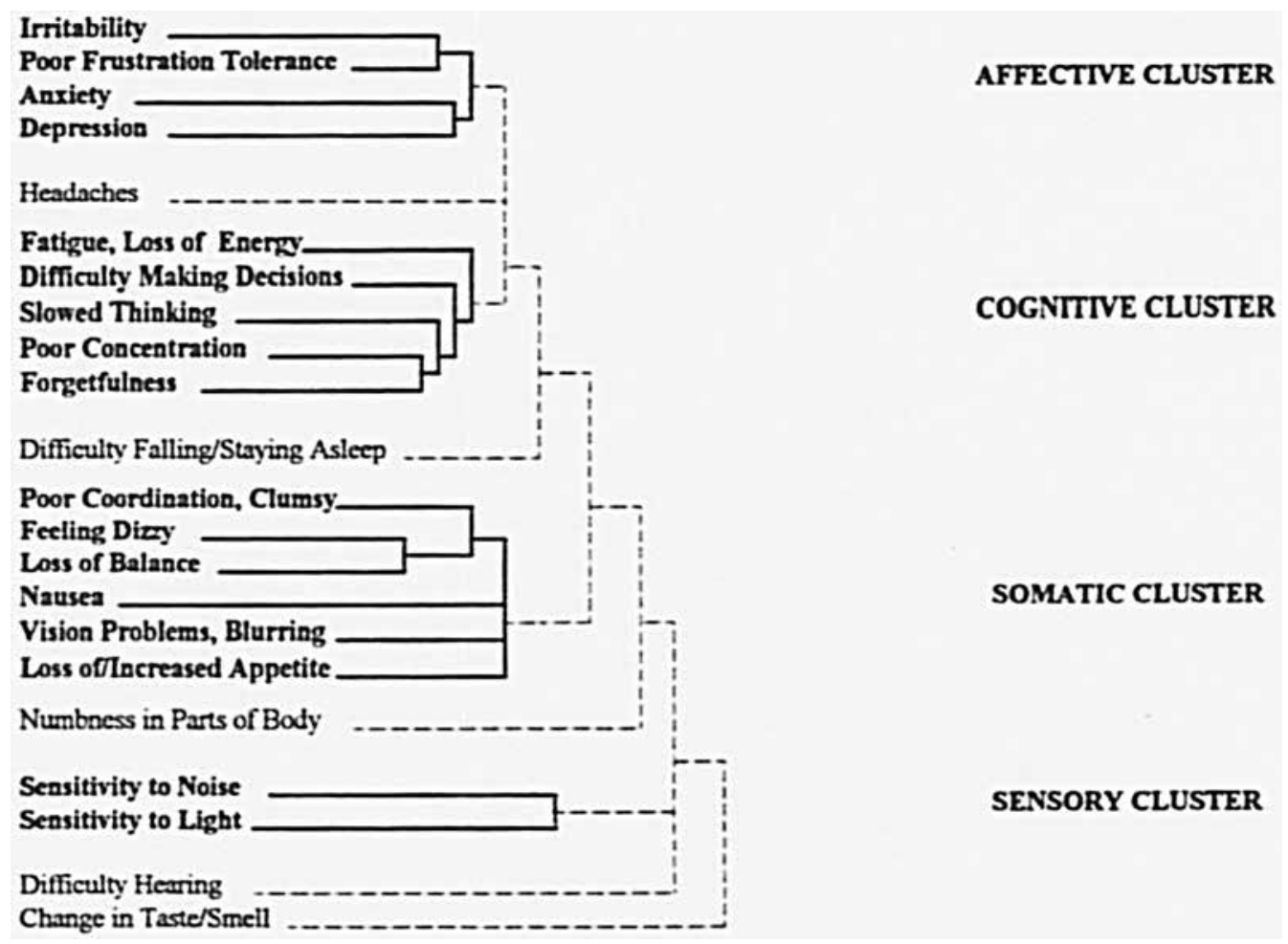

Fig. 1. Symptoms of post-concussion syndrome in mild traumatic brain injury (according to K.D. Cicerone and K. Kalmar [13]) 
Table 1. Frequency of detection and severity of symptoms and signs in patients with post-concussion syndrome

\begin{tabular}{|c|c|c|c|c|c|c|c|c|c|}
\hline \multirow{3}{*}{ №* } & \multirow{3}{*}{ Symptom, sign } & \multicolumn{8}{|c|}{ Detection rate } \\
\hline & & \multicolumn{2}{|c|}{$\begin{array}{c}\text { rarely, } \\
\text { does not affect } \\
\text { working capacity }\end{array}$} & \multicolumn{2}{|c|}{$\begin{array}{c}\text { frequently, } \\
\text { sometimes } \\
\text { impairs working } \\
\text { capacity }\end{array}$} & \multicolumn{2}{|c|}{$\begin{array}{l}\text { very frequent, } \\
\text { possible } \\
\text { disability }\end{array}$} & \multicolumn{2}{|c|}{$\begin{array}{l}\text { constantly, } \\
\text { unable to work }\end{array}$} \\
\hline & & Abs. & $\%$ & Abs. & $\%$ & Abs. & $\%$ & Abs. & $\%$ \\
\hline $1 \mathrm{C}$ & Dizziness & 43 & 37,4 & 62 & 53,9 & 9 & 7,8 & 0 & 0 \\
\hline $2 \mathrm{C}$ & Loss of balance & 74 & 64,3 & 21 & 18,3 & 3 & 2,6 & 1 & 0,9 \\
\hline $3 \mathrm{C}$ & $\begin{array}{l}\text { Impaired motor coordination, } \\
\text { clumsiness }\end{array}$ & 72 & 62,6 & 12 & 10,4 & 10 & 8,7 & 1 & 0,9 \\
\hline 4 & Headaches & 27 & 23,5 & 55 & 47,8 & 22 & 19,1 & 10 & 8,7 \\
\hline $5 \mathrm{C}$ & Nausea & 75 & 65,2 & 17 & 14,8 & 3 & 2,6 & 1 & 0,9 \\
\hline $6 \mathrm{C}$ & Trouble seeing, blurred vision & 66 & 57,4 & 15 & 13,0 & 10 & 8,7 & 5 & 4,3 \\
\hline 7 & High sensitivity to light & 62 & 53,9 & 12 & 10,4 & 8 & 7,0 & 4 & 3,5 \\
\hline 8 & Hearing difficulty & 41 & 35,7 & 50 & 43,5 & 11 & 9,6 & 9 & 7,8 \\
\hline 9 & High sensitivity to noise & 73 & 63,5 & 20 & 17,4 & 8 & 7,0 & 7 & 6,1 \\
\hline 10 & Numbness or tingling in the body & 62 & 53,9 & 13 & 11,3 & 7 & 6,1 & 6 & 5,2 \\
\hline 11 & Changes in taste or smell & 31 & 27,0 & 7 & 6,1 & 6 & 5,2 & 2 & 1,7 \\
\hline 12 & Loss of appetite or its increase & 39 & 33,9 & 15 & 13,0 & 4 & 3,5 & 6 & 5,2 \\
\hline $13 \mathrm{~K}$ & Poor concentration & 24 & 20,9 & 64 & 55,7 & 19 & 16,5 & 8 & 7,0 \\
\hline $14 \mathrm{~K}$ & $\begin{array}{l}\text { Forgetfulness, inability to } \\
\text { remember certain things }\end{array}$ & 31 & 27,0 & 55 & 47,8 & 23 & 20,0 & 6 & 5,2 \\
\hline $15 \mathrm{~K}$ & Difficulty making decisions & 48 & 41,7 & 55 & 47,8 & 11 & 9,6 & 1 & 0,9 \\
\hline $16 \mathrm{~K}$ & $\begin{array}{l}\text { Slowing down thoughts, inability } \\
\text { to push the matter through }\end{array}$ & 16 & 13,9 & 58 & 50,4 & 35 & 30,4 & 5 & 4,3 \\
\hline $17 \mathrm{~K}$ & $\begin{array}{l}\text { Exhaustion, decreased energy, } \\
\text { rapid fatigability }\end{array}$ & 12 & 10,4 & 50 & 43,5 & 37 & 32,2 & 16 & 13,9 \\
\hline $18 \mathrm{~A}$ & $\begin{array}{l}\text { Feeling of anxiety, nervous and } \\
\text { psychic tension }\end{array}$ & 21 & 18,3 & 59 & 51,3 & 29 & 25,2 & 6 & 5,2 \\
\hline $19 \mathrm{~A}$ & $\begin{array}{l}\text { Difficulty falling asleep, touble } \\
\text { sleeping }\end{array}$ & 6 & 5,2 & 34 & 29,6 & 44 & 38,3 & 31 & 27,0 \\
\hline $20 \mathrm{~A}$ & Feeling depressed or distress & 20 & 17,4 & 58 & 50,4 & 31 & 27,0 & 6 & 5,2 \\
\hline $21 \mathrm{~A}$ & High irritability & 22 & 19,1 & 62 & 53,9 & 24 & 20,9 & 6 & 5,2 \\
\hline $22 \mathrm{~A}$ & $\begin{array}{l}\text { Feeling frustrated with little } \\
\text { things }\end{array}$ & 35 & 30,4 & 62 & 53,9 & 13 & 11,3 & 3 & 2,6 \\
\hline
\end{tabular}

* - Questionnaire item (based on [13]), used to calculate scores by clusters: S - somatic disorders; C - cognitive disorders; A - affective disorders.

were identified: 1-5 points - mild impairments, which do not affect working capacity, 6-10 points - moderate impairments, sometimes impair the ability to work, 11-15 points - significant impairments of working capacity, 16-20 points - significant impairments, the patient can not work and needs help.
Differentiated assessment of the presence and severity of cognitive impairment allowed us to identify three clinical variants of PCS. In $51(44.3 \pm 9.1) \%$ of patients, the first variant of PCS with the predominance of cognitive impairment was identified, which was characterized in $(7.0 \pm 4.6) \%$ of patients with significant 
(16-20 scores) cognitive impairment, in (37.4 \pm 8.8$) \%$ - severe (11-15 points) in combination with significant and severe affective disorders. The second variant of PCS with the predominance of severe and significant affective disorders and moderate cognitive impairment was found in $27(23.5 \pm 7.7) \%$ patients, the third variant, which was characterized by moderate and mild disorders of cognitive and affective spectrum in combination with predominantly moderate autonomic disorders - 37 (32.2 \pm $8.5) \%$ ) patients (the variant of PCS with the predominance of psychosomatic disorders). Only $4(3.5 \pm 3.3) \%$ patients had somatic disorders as the leading cause of disability.

The variants of PCS identified by us on many characteristics coincide with three classical clusters (affective, cognitive and somatic) in the structure of non-combat injuries according to K.D. Cicerone and K. Kalmar [13]. The fourth ("sensory") cluster in our study occurred infrequently. The cognitive impairments that were the object of our interest did not differ.
In Fig. 2 the frequency of impairments of varying severity in our selected clinical variants of PCS is shown. When establishing the diagnosis of PCS, in our opinion, it is advisable to use more detailed information highlighting the variant of the course as the component of the classification and taking into account the severity of damage to elements in the cluster. We used the coding in the form of "CAS", where the position of the figure corresponds to the level of injury in the cluster ("C" cognitive, "A" - affective, "S" - somatic). For example, "122" means "significant" damage to cognitive and affective clusters and "severe" somatic disorders, "331" means "moderate" damage to cognitive and affective clusters and "significant" somatic disorders.

The isolation of the PCS variant with the predominance of cognitive impairment allowed us to monitor the relationship between the results of neurophysiological studies and the neurocognitive indicators of patients with BMTBI. We aimed to determine the diagnostic

\begin{tabular}{|c|c|c|c|c|c|c|}
\hline \multicolumn{4}{|c|}{ The level of injury in the cluster } & \multicolumn{2}{|c|}{ Frequency } & \multirow{2}{*}{$\begin{array}{c}\text { Frequency, } \\
95 \% \mathrm{CI}\end{array}$} \\
\hline CAS $^{*}$ & $\bar{C}$ & A & $\mathrm{s}$ & Abs. & $\%$ & \\
\hline 112 & & & & 2 & 1,7 & \multirow{12}{*}{$\begin{array}{l}\text { The first variant of } \\
\text { PCS with the } \\
\text { predominance of } \\
\text { cognitive impairment } \\
44,3 ; \\
9,1\end{array}$} \\
\hline 113 & & & & 1 & 0,9 & \\
\hline 122 & & & & 3 & 2,6 & \\
\hline 123 & & & & 2 & 1,7 & \\
\hline 212 & & & & 1 & 0,9 & \\
\hline 213 & & & & 5 & 4,3 & \\
\hline 222 & & & & 6 & 5,2 & \\
\hline 223 & & & & 10 & 8,7 & \\
\hline 224 & & & & 13 & 11,3 & \\
\hline 232 & & & & 2 & 1,7 & \\
\hline 233 & & & & 4 & 3,5 & \\
\hline 234 & & & & 2 & 1,7 & \\
\hline 313 & & & & 1 & 0,9 & \multirow{4}{*}{$\begin{array}{l}\text { The second variant of } \\
\text { PCS with the } \\
\text { predominance of } \\
\text { affective disorders } \\
23,5 \\
7,7\end{array}$} \\
\hline 322 & & & & 2 & 1,7 & \\
\hline 323 & & & & 12 & 10,4 & \\
\hline 324 & & & & 12 & 10,4 & \\
\hline 331 & & & & 1 & 0,9 & \multirow{6}{*}{$\begin{array}{l}\text { The third variant of } \\
\text { PCS with the } \\
\text { predominance of } \\
\text { psychosomatic } \\
\text { disorders } \\
32,2 \\
8,5\end{array}$} \\
\hline 332 & & & & 3 & 2,6 & \\
\hline 333 & & & & 10 & 8,7 & \\
\hline 334 & & & & 20 & 17,4 & \\
\hline 344 & & & & 1 & 0,9 & \\
\hline 433 & & & & 2 & 1,7 & \\
\hline
\end{tabular}

* - the level of injury in the cluster (1- significant; 2 - severe; 3 - moderate; 4 - mild)

Fig. 2. Frequency of impairments of varying severity in patients (explanation in the text) 
value of some of the most common complaints and pathological signs in the cognitive cluster and deviations from the norm of CEP 300 indicators. It is generally accepted to recognize the capability of the CEP 300 method to objectively assess certain indicators in attention and memory domains $[16,17]$. Since the P300 latency in patients with significant and severe cognitive impairment did not differ statistically significantly, they were considered as one group: the sum of scores 11-20 corresponded to the degree of impairments that interfere with work until complete inability to work. The P300 CEP indicators in these patients were compared with indicators of patients with mild cognitive impairment (1-10 scores) that did not interfere with work.

According to our study, the P300 latency indices are inversely proportionally correlated with the assessment in the cognitive cluster (sum of scores) obtained when assessing symptoms (signs) using the questionnaire "Cicerone": on the left $\rho=0.94, p=0.001$; on the right $\rho=0.67, p=0.004$. P300 latency indices statistically significantly depended on the severity of cognitive disorders: on the right $-U=1246, p=0.03$; on the left $-\mathrm{U}=1245, \mathrm{p}=0.03$.

Indicators of patients with severe cognitive impairment were: CEP P300 latency on the right - 357 (341-403) ms, on the left - $362(338-395) \mathrm{ms}$, the amplitude of CEP P300 on the right - $4.4(3.2-7.6) \mu \mathrm{V}$, on

\section{Left hemisphere}

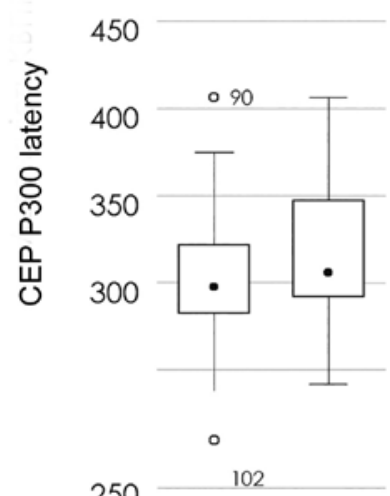

250

200

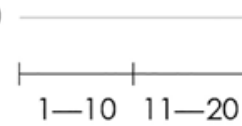

Right hemisphere

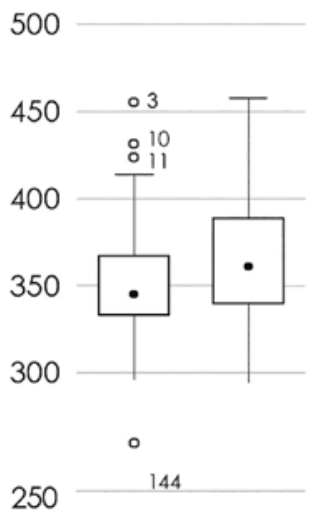

200

$$
1-10 \quad 11-20
$$

Severity of cognitive impairment, score

\section{- Median;}

$$
\square \text { Q1 - Q3; }
$$

- Min - max (within 1.5 interquartile range);

- Outliers distant from Q1 and Q3

are not closer than 1.5 and not farther than 3

interquartile ranges

Fig. 3. Latency of CEP P300 in patients with varying degrees of severity in cognitive clusters the left $-4.3(3.2-6.9) \mu \mathrm{V}$, patients with mild cognitive impairment - 357 (330-374) $\mathrm{ms}(U=1246, \mathrm{p}=0.03)$ and 345 (331-370) ms, $4.3(3.1-6.0)$ and 4.7 (3.4-7.6) $\mu \mathrm{V}$ respectively.

In Fig. 3 the results of mathematical processing of the obtained data on the latency of P300 in patients with varying degrees of severity of cognitive impairment are shown.

\section{Conclusions}

The method of cognitive evoked potentials P300 can be an effective means of objectifying the degree of cognitive impairment in patients with post-concussion syndrome due to blast mild traumatic brain injury.

\section{Disclosure}

\section{Conflict of interest}

The authors declare no conflict of interest.

Ethical approval

All procedures performed in studies involving human participants were in accordance with the ethical standards of the institutional and national research committee and with the 1964 Helsinki declaration and its later amendments or comparable ethical standards.

Informed consent

The written informed consent was obtained from each patient or appropriate family member before the surgery.

Funding

The research had no sponsor support.

\section{References}

1. Kobeissy $F$, Mondello $S$, Tümer $N$, Toklu $H Z$, Whidden MA, Kirichenko N, Zhang Z, Prima V, Yassin W, Anagli J, Chandra N, Svetlov S, Wang KK. Assessing neuro-systemic \& behavioral components in the pathophysiology of blastrelated brain injury. Front Neurol. 2013 Nov 21;4:186. doi: 10.3389/fneur.2013.00186

2. Hoge CW, McGurk D, Thomas JL, Cox AL, Engel CC, Castro CA. Mild traumatic brain injury in U.S. Soldiers returning from Iraq. N Engl J Med. 2008 Jan 31;358(5):453-63. doi: 10.1056/NEJMoa072972

3. Owens BD, Kragh JF Jr, Wenke JC, Macaitis J, Wade CE, Holcomb JB. Combat wounds in operation Iraqi Freedom and operation Enduring Freedom. J Trauma. 2008 Feb;64(2):295-9. doi: 10.1097/TA.0b013e318163b875

4. Elder GA. Update on TBI and Cognitive Impairment in Military Veterans. Curr Neurol Neurosci Rep. 2015 Oct;15(10):68. doi: 10.1007/s11910-015-0591-8

5. Phipps $\mathrm{H}$, Mondello $\mathrm{S}$, Wilson $A$, Dittmer $\mathrm{T}$, Rohde $N N_{\text {, }}$ Schroeder PJ, Nichols J, McGirt C, Hoffman J, Tanksley K, Chohan M, Heiderman A, Abou Abbass H, Kobeissy F, Hinds S. Characteristics and Impact of U.S. Military Blast-Related Mild Traumatic Brain Injury: A Systematic Review. Front Neurol. 2020 Nov 2;11:559318. doi: 10.3389/ fneur.2020.559318

6. Sirko A, Pilipenko G, Romanukha D, Skrypnik A. Mortality and Functional Outcome Predictors in Combat-Related Penetrating Brain Injury Treatment in a Specialty Civilian Medical Facility. Mil Med. 2020 Jun 8;185(5-6):e774-e780. doi: $10.1093 / \mathrm{milmed} / \mathrm{usz} 431$

7. Kucherov Y, Hubler GK, DePalma RG. Blast induced mild traumatic brain injury/concussion: a physical analysis. Journal of Applied Physics. 2012 Nov 15;112(10):104701. doi: 10.1063/1.4765727

8. Benzinger TL, Brody $D$, Cardin S, Curley KC, Mintun MA, Mun SK, Wong KH, Wrathall JR. Blast-related brain injury: imaging for clinical and research applications: report of the 2008 st. Louis workshop. J Neurotrauma. 2009 Dec:26(12):2127-44. doi: 10.1089/neu.2009.0885

9. Veitch DP, Friedl KE, Weiner MW. Military risk factors for 
cognitive decline, dementia and Alzheimer's disease. Curr Alzheimer Res. 2013 Nov;10(9):907-30. doi: 10.2174/15672050113109990142

10. Karr JE, Areshenkoff CN, Duggan EC, Garcia-Barrera MA. Blast-related mild traumatic brain injury: a Bayesian random-effects meta-analysis on the cognitive outcomes of concussion among military personnel. Neuropsychol Rev. 2014 Dec;24(4):428-44. doi: 10.1007/s11065-014-9271-8

11. Dwyer B, Katz DI. Postconcussion syndrome. Handb Clin Neurol. 2018;158:163-178. doi: 10.1016/B978-0-44463954-7.00017-3

12. Elder GA, Mitsis EM, Ahlers ST, Cristian A. Blast-induced mild traumatic brain injury. Psychiatr Clin North Am. 2010 Dec;33(4):757-81. doi: 10.1016/j.psc.2010.08.001

13. Cicerone KD, Kalmar K. Persistent postconcussion syndrome: the structure of subjective complaints after mild traumatic brain injury. The Journal of head trauma rehabilitation. 1995;10(3):1-17. doi: 10.1097/00001199199510030-00002

14. Zakharov VV. [Neuro-psychiatric disorders: diagnostic tests]. Moscow: MEDpress-inform. 2013. Russian.

15. Solovyova AP, Goryachev DV, Arkhipov VV. [Criteria for assessment of cognitive impairment in clinical trials]. The Bulletin of the Scientific Centre for Expert Evaluation of Medicinal Products. 2018 Nov 22;8(4):218-30. doi:10.30895/1991-2919-2018-8-4-218-230.

16. Kropotov YD. [Quantitative EEG, event related potentials and neurotherapy]. Donetsk: Publisher Zaslavsky AY. 2010. Russian.

17. Gnezditskiy VV, Korepina OS, Chatskaya AV, Klochkova OI. [Memory, Cognition and the Endogenous Evoked Potentials of the Brain: the Estimation of the Disturbance of Cognitive Functions and Capacity of Working Memory Without the Psychological Testing]. Uspekhi fiziologicheskikh nauk. 2017 Jan 1;48(1):3-23. Russian.

18. Chebotariova LL, Solonovych OS, Kadzhaya MV, Tretiakova AI, Solonovych AS, Pronoza-Stebliuk KV, Stebliuk VV. [Risk factors of cognitive impairment in patients with blast-related mild traumatic brain injury]. Ukrainian Neurosurgical Journal. 2019;25(4):16-24. Ukrainian. doi: $10.25305 /$ unj.174610

19. Chebotariova LL, Tretiakova AI, Solonovych AS, Sulii LM, Zol'nikova AY. Post-concussion syndrome after a mine blast injury: neuropsychological consequences and changes of the cognitive evoked potentials (P 300). Neurophysiology. 2020 Jul;52(4):289-97. doi: 10.1007/s11062-021-09884-7 